\title{
Crystal structure of yttrium nickel phosphide, $\mathbf{Y}_{20} \mathbf{N i}_{42} \mathbf{P}_{\mathbf{3 0 . 3 4}}$
}

\author{
S. Stoyko', S. Oryshchyn ${ }^{I}$, V. Babizhetskyy*,II and R. Guérin ${ }^{\text {III }}$ \\ I Ivan Franko National University of Lviv, Department of Analytical Chemistry, Kyryla i Mefodiya Street 6, 79005 Lviv, Ukraine \\ II Max-Planck-Institut für Festkörperforschung, Heisenbergstraße 1, 70569 Stuttgart, Germany \\ III Université de Rennes 1, Sciences Chimiques de Rennes, UMR 6226 CNRS, Avenue du Général Leclerc, 35042 Rennes Cedex, France
}

Received July 19th, 2006, accepted and available on-line August 10, 2006; CSD no. 409887

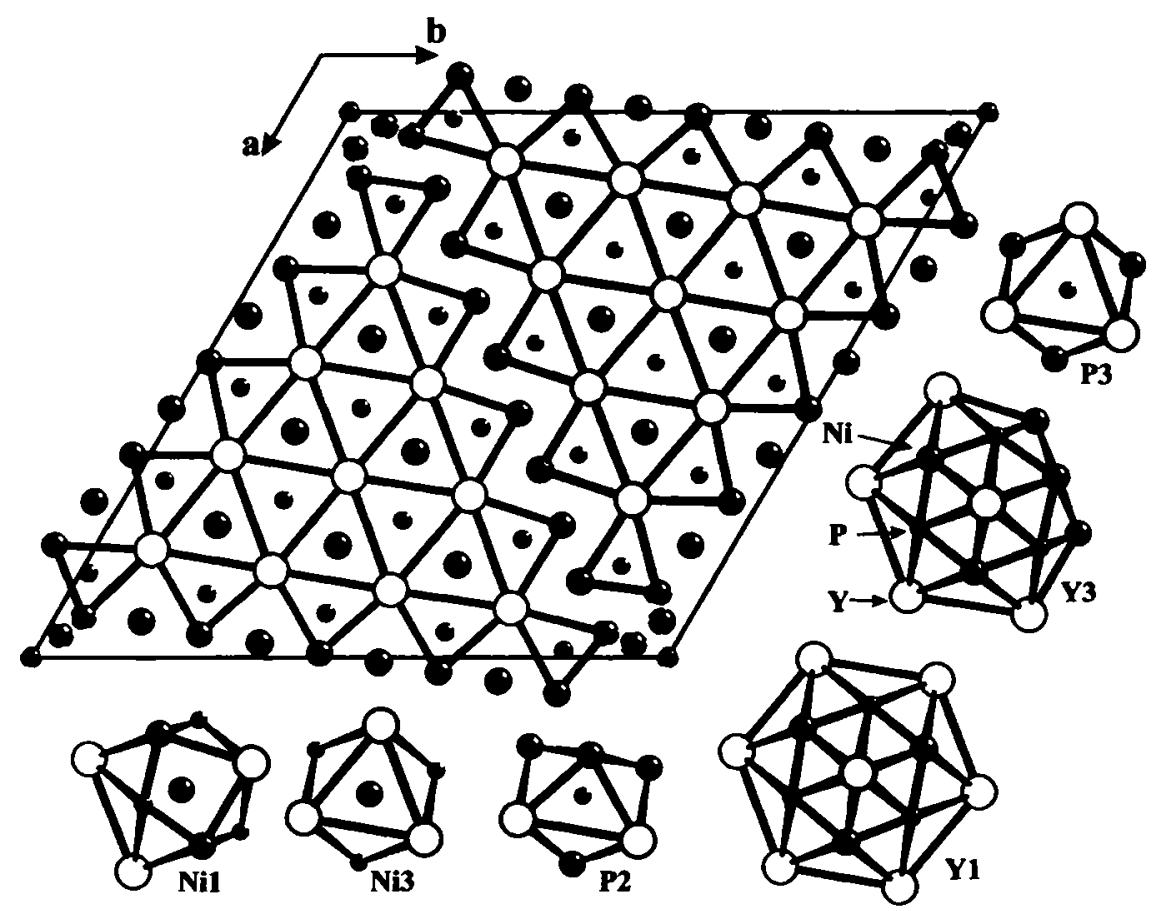

Abstract

$\mathrm{Ni}_{42} \mathrm{P}_{30.34} \mathrm{Y}_{20}$, hexagonal, $P 6_{3} / \mathbf{m}$ (no. 176),

$a=20.270(1) \AA, c=3.8030(2) \AA, V=1353.2 \AA^{3}, Z=1$, $R_{\mathrm{gt}}(F)=0.053, w R_{\mathrm{ref}}\left(F^{2}\right)=0.122, T=293 \mathrm{~K}$.

\section{Source of material}

A mixture of yttrium ingots, red phosphorous and nickel powders (all with minimum purity $99.95 \%$ ) was wrapped in a molibdenum foil, gradually heated to $1070 \mathrm{~K}$ in sealed evacuated quartz tube and kept at this temperature for $2 \mathrm{~d}$. Subsequently, the sample was melted in an arc furnace under a Ti-gettered argon atmosphere. Needle-like single crystals of the title compound were extracted from the crushed alloy.

\section{Experimental details}

Samples were characterized by $\mathrm{X}$-ray powder diffraction (Huber Image Plate Guinier camera $\mathrm{G} 670, \mathrm{CuK} K_{\alpha 1}$ radiation, $\lambda=1.54056 \AA$, $8^{\circ} \leq 2 \theta \leq 100^{\circ}$, Ge as internal standard, $a=5.657905 \AA$ ).

\section{Discussion}

The crystal structure of a new ternary phosphide $\mathbf{Y}_{20} \mathrm{Ni}_{42} \mathrm{P}_{31}$ adopts the $\mathrm{Sm}_{20} \mathrm{Ni}_{41.6} \mathrm{P}_{30}$ type [1] and belongs to the homologous family of flat hexagonal two-net structures with a metal/nonmetal ratio equal or close to 2 and with the general chemical for-

\footnotetext{
* Correspondence author (e-mail: v.babizhetskyy@fkf.mpg.de)
}

mula $R_{n(n-1)} T_{(n+1)(n+2)} X_{n(n+1)+1}(R$ - rare earth metal, $T$ - transition metal, $X$ - main group element, $n=1-6)[2-4]$.

For the structural description of $\mathrm{Y}_{20} \mathrm{Ni}_{42} \mathrm{P}_{31}$, one can consider the stacking of trigonal prisms formed by the $\mathrm{Y}$ and $\mathrm{Ni}$ atoms and centered by $P$ ones. The trigonal prisms, connected only by common edges, are arranged in two identical fragments " $\mathrm{Y}_{10} \mathrm{Ni}_{21} \mathrm{P}_{15}$ " centered on the three-fold axes and mutually displaced by $\mathrm{c} / 2$ (cf. figure). The coordination number (CN) is 20 for all $\mathrm{Y}$ atoms, while for the $\mathrm{Ni}$ atoms $\mathrm{CN}=9(\mathrm{Ni3}, \mathrm{Ni} 5$ and $\mathrm{Ni} 6), 12(\mathrm{Ni1}, \mathrm{Ni} 2$ and Ni4) and 15 (Ni7 and Ni8). Finally, the $P$ atoms (P1-P5) are in tricapped trigonal prisms $(\mathrm{CN}=9)$, while the $\mathrm{P6}$ one on the sixfold axis occupies the center of a somewhat octahedral site. The shortest interatomic distances observed $d(\mathrm{Ni5}-\mathrm{P} 1)=2.213(7) \AA$, $d(\mathrm{Ni} 2-\mathrm{Ni7})=2.488(6) \AA, d(\mathrm{Y} 4-\mathrm{P} 5)=2.877(5) \AA$ and $d(\mathrm{Y} 4-\mathrm{NiS})=2.918(3) \AA$ are the same order of magnitude than those observed in the crystal structures of all the ternary rareearth nickel phosphides and the average distances $Y-P, N i-P$, $\mathrm{Y}-\mathrm{Ni}$ and $\mathrm{Ni}-\mathrm{Ni}$ are in good agreement with the sum of metallic radii of $\mathrm{Y}(1.77 \AA)$ and/or $\mathrm{Ni}(1.24 \AA)$ and the covalent radius of P (1.10 $\AA)$.

The splitting of the $\mathrm{Ni}$ atoms around the sixfold axis in two $6 h$ positions partially occupied is due to the splitting of the P6 atom on this axis (one $2 b$ position half occupied, since the sites at $z=0$ and $z=1 / 2$ cannot be occupied at the same time. Such a metalloid disorder on $0,0, z$ coupled to that of the surrounding metal atoms is frequently found in binary or ternary pnictides having hexagonal symmetry and a metal/metalloid ratio equal or close to $2[5,6]$. 
Table 1. Data collection and handling.

\begin{tabular}{ll}
\hline Crystal: & shiny silvery gray needle, \\
& size $0.01 \times 0.01 \times 0.24 \mathrm{~mm}$ \\
Wavelength: & Mo $K_{a}$ radiation $(0.71073 \AA)$ \\
$\mu:$ & $361.4 \mathrm{~cm}^{-1}$ \\
Diffractometer, scan mode: & Nonius KappaCCD, $\omega$ \\
$2 \theta_{\max }:$ & $50.02^{\circ}$ \\
$N(h k l)_{\text {mersured, }} N(h k l)_{\text {unique }}:$ & 3209,934 \\
Criterion for $I_{\text {obss }} N(h k l)_{\text {gt: }}:$ & $I_{\text {obs }}>2 \sigma\left(I_{\text {obs }}\right), 507$ \\
$N(p a r a m)_{\text {refined: }}$ & 98 \\
Programs: & SIR97 [7], SHELXL-97 [8], DLAMOND [9] \\
\hline
\end{tabular}

Table 2. Atomic coordinates and displacement parameters (in $\AA^{2}$ ).

\begin{tabular}{lllllll}
\hline Atom & Site & Occ. & $x$ & $y$ & $z$ & $U_{\text {iso }}$ \\
\hline Ni(8) & $6 h$ & 0.18 & $0.027(1)$ & $0.071(2)$ & $3 / 4$ & $0.021(5)$ \\
$\mathrm{P}(6)$ & $2 b$ & 0.17 & 0 & 0 & $1 / 2$ & $0.02(2)$
\end{tabular}

Table 3. Atomic coordinates and displacement parameters (in $\AA^{2}$ ).

\begin{tabular}{|c|c|c|c|c|c|c|c|c|c|c|c|}
\hline Atom & Site & Occ. & $x$ & $y$ & $z$ & $U_{11}$ & $U_{22}$ & $U_{33}$ & $U_{12}$ & $U_{13}$ & $U_{23}$ \\
\hline $\mathbf{Y}(1)$ & $2 c$ & & $1 / 3$ & $2 / 3$ & $3 / 4$ & $0.012(2)$ & $U_{11}$ & $0.008(2)$ & $1 / 2 U_{11}$ & 0 & 0 \\
\hline$Y(2)$ & $6 h$ & & $0.1607(1)$ & $0.7020(1)$ & $3 / 4$ & $0.009(1)$ & $0.010(1)$ & $0.011(1)$ & $0.004(1)$ & 0 & 0 \\
\hline $\mathbf{Y}(3)$ & $6 h$ & & $0.3716(1)$ & $0.8756(1)$ & $3 / 4$ & $0.009(2)$ & $0.009(2)$ & $0.010(1)$ & $0.003(1)$ & 0 & 0 \\
\hline $\mathbf{Y}(4)$ & $6 h$ & & $0.1994(1)$ & $0.9093(1)$ & $3 / 4$ & $0.015(2)$ & $0.010(1)$ & $0.010(1)$ & $0.006(1)$ & 0 & $\mathbf{0}$ \\
\hline $\mathrm{Ni}(1)$ & $6 h$ & & $0.0270(2)$ & $0.6543(2)$ & $1 / 4$ & $0.012(2)$ & $0.011(2)$ & $0.013(2)$ & $0.004(2)$ & 0 & $\mathbf{0}$ \\
\hline $\mathrm{Ni}(2)$ & $6 h$ & & $0.0665(2)$ & $0.8601(2)$ & $1 / 4$ & $0.008(2)$ & $0.013(2)$ & $0.016(2)$ & $0.003(2)$ & 0 & 0 \\
\hline $\mathrm{Ni}(3)$ & $6 h$ & & $0.4151(2)$ & $0.7936(2)$ & $1 / 4$ & $0.008(2)$ & $0.010(2)$ & $0.012(1)$ & $0.004(2)$ & 0 & 0 \\
\hline $\mathrm{Ni}(4)$ & $6 h$ & & $0.0082(2)$ & $0.5511(2)$ & $3 / 4$ & $0.012(2)$ & $0.011(2)$ & $0.011(2)$ & $0.007(2)$ & $\mathbf{0}$ & $\mathbf{0}$ \\
\hline $\mathrm{Ni}(5)$ & $6 h$ & & $0.2433(2)$ & $0.8289(2)$ & $1 / 4$ & $0.007(2)$ & $0.008(2)$ & $0.012(1)$ & $0.004(2)$ & $\mathbf{0}$ & 0 \\
\hline $\mathrm{Ni}(6)$ & $6 h$ & & $0.0432(2)$ & $0.7566(2)$ & $1 / 4$ & $0.012(2)$ & $0.013(2)$ & $0.014(2)$ & $0.007(2)$ & $\mathbf{0}$ & 0 \\
\hline $\mathbf{N i}(7)$ & $6 h$ & 0.82 & $-0.0452(2)$ & $0.8798(3)$ & $1 / 4$ & $0.007(2)$ & $0.022(3)$ & $0.022(2)$ & $0.008(2)$ & $\mathbf{0}$ & $\mathbf{0}$ \\
\hline$P(1)$ & $6 h$ & & $0.3254(3)$ & $0.9528(4)$ & $1 / 4$ & $0.012(4)$ & $0.011(4)$ & $0.005(3)$ & $0.007(3)$ & $\mathbf{0}$ & $\mathbf{0}$ \\
\hline$P(2)$ & $6 h$ & & $0.1182(3)$ & $0.7825(4)$ & $1 / 4$ & $0.006(4)$ & $0.008(4)$ & $0.010(3)$ & $0.003(3)$ & $\mathbf{0}$ & 0 \\
\hline $\mathbf{P}(3)$ & $6 h$ & & $0.2895(4)$ & $0.7478(4)$ & $1 / 4$ & $0.008(4)$ & $0.002(3)$ & $0.008(2)$ & $0.003(3)$ & 0 & $\mathbf{0}$ \\
\hline $\mathbf{P}(4)$ & $6 h$ & & $0.4958(4)$ & $0.9187(4)$ & $1 / 4$ & $0.008(4)$ & $0.003(3)$ & $0.007(2)$ & $0.000(3)$ & $\mathbf{0}$ & $\mathbf{0}$ \\
\hline$P(5)$ & $6 h$ & & $-0.1688(4)$ & $0.8439(4)$ & $1 / 4$ & $0.015(4)$ & $0.012(4)$ & $0.014(3)$ & $0.008(3)$ & $\mathbf{0}$ & $\mathbf{0}$ \\
\hline
\end{tabular}

\section{References}

1. Chykhrij, I.; Babizhetskyy, V.; Oryshchyn, S.; Aksel'rud, L.; Kuz'ma, Yu.: $\mathrm{Sm}_{20} \mathrm{Ni}_{41.6} \mathrm{P}_{30}$ and $\mathrm{Tb}_{15} \mathrm{Ni}_{28} \mathrm{P}_{21}$ - new members of homologous series of hexagonal two-net structures. Kristallographiya 38 (1993) 262-265.

2. Pivan, J. Y.; Guérin, R.: Synthesis and structure determination of (La,Ce) ${ }_{12}$ Rh30 $_{21}$. J. Less-Common Met. 120 (1986) 247-254.

3. Yarmolyuk, Ya.; Aksel'rud, L.: Homologous series of flat hexagonal (two-layer) structures. Kristallographiya 28 (1983) 1111-1117.

4. Pivan, J. Y.; Guérin, R.: $M_{2} X$ Intermetallics: Nonmetal Insertion in a h.c.Like Metallic Distribution. J. Solid State Chem. 135 (1998) 218-227.

5. Le Sénechal, C.; Babizhetskyy, V.; Députier, S.; Pivan, J. Y.; Guérin, R.: Crystal Chemistry of defective intermetallics with empty triangular metalloid channels: the new phosphide $\mathrm{Zr}_{6} \mathrm{Cr}_{60} \mathrm{P}_{39}$. J. Solid State Chem. 144 (1999) 277-286.
6. Stoyko,S.; Oryshchyn, S.; Babizhetskyy, V.; Guérin, R.: Crystal structure of a new ternary phosphide $\mathrm{Y}_{6} \mathrm{Ni}_{15-x} \mathrm{P}_{10+y}(x=0.08, y=0.18)$. J. Alloys Compd. 367 (2004) 156-161.

7. Altomare, A.; Burla, M. C.; Camalli, M.; Carroccini, B.; Cascarano, G. L.; Giacovazzo, C.; Guagliardi, A.; Moliterni, A. G.; Polidori, G.; Rizzi, R.: SIR97: A new tool for structure determination and refinement. J. Appl. Crystallogr. 32 (1999) 115-119.

8. Sheldrick, G. M.: SHELXL-97. Program for the Refinement of Crystal Structures. University of Göttingen, Germany 1997.

9. Brandenburg, K.: DLAMOND. Visual Crystal Structure Information System. Version 2.1e. Crystal Impact, Bonn, Germany 2001. 